\title{
PERBANDINGAN HASIL PERENCANAAN TEBAL PERKERASAN JALAN TIPE PERKERASAN KAKU ANTARA METODE AASHTO 1993 DENGAN METODE Pd.T.14-2003 PADA PERENCANAAN JALAN RADEN FATAH JAMBI
}

\author{
Reza Sucinda, M.Asmuni Jatoeb, Huzeirien. M \\ Program Studi Teknik Sipil Universitas Batanghari \\ asmunijatoeb@gmail.com
}

\begin{abstract}
Abstrak
Perencanaan perkerasan kaku terdapat dua metode yang sangat dikenal di Indonesia dan sering dipakai untuk merencanakan suatu jalan yang menggunakan perkerasan kaku, yaitu Metode AASHTO 1993 dan Metode Pd.T.4-2003. Peneliti ingin membandingkan kedua metode diatas dengan objek penelitian di ruas jalan Raden Fatah Kec.Jambi Timur Kota Jambi. Permasalahan yang dikemukakan adalah Bagaimana alternatif desain rigid pavement metode AASHTO 1993 dan Pd.T.14-2003 dari parameter-parameter perencanaan. Berapa tebal perkerasan yang dibutuhkan pada rigid pavement metode AASHTO 1993 dan Pd.T.14-2003 dan membandingkan tebal perencanaan perkerasan kaku Rigid Pavement antara metode AASHTO 1993 dan Pd.T.14-2003 pada jalan Raden Fatah Kota Jambi. Untuk mendukung penelitian diatas diawali dengan pengumpulan data skunder, yaitu data-data yang diperoleh dari data yang telah ada berupa catatan dan laporan seperti nilai CBR sebesar $6 \%$, eksisting $=20 \mathrm{~cm}$ dan data survei LHR terbaru tahun 2017 yang telah didapat. Hasil analisa traffic ruas jalan Raden Fatah pada perencanaan 20 tahun sebesar 1174584217 ESAL. Tebal perkerasan yang didapat dari metode AASHTO 1993 sebesar $23 \mathrm{~cm}$, sedangkan tebal perkerasan yang didapat metode Pd.T.14-2003 Sebesar $22 \mathrm{~cm}$. Hasil penelitian menunjukan bahwa tebal eksisting tersebut aman digunakan selama umur rencana (20 tahun). Meskipun ada beberapa paramater yang berbeda, hal ini dikarenakan parameterparameter tersebut disesuaikan masing-masing negara dimana metode tersebut diciptakan. Namun kedua metode ini sama-sama didasarkan pada kemampuan beton dalam menahan beban lentur.
\end{abstract}

Kata Kunci : AASHTO 1993, Pd.T.14-2003,LHR, VDF,ESAL,Fatik dan Erosi

\section{PENDAHULUAN}

Di Indonesia ada dua metode perencanaan perkerasan kaku yang sering digunakan yaitu Metode American Association of State Highway and Tranportation Officials (AASHTO ) tahun 1993 dan Metode Pd.T. 14-2003 yang dipakai oleh Kementerian Pekerjaan Umum Republik Indonesia Direktorat Jenderal Bina Marga. Parameter-parameter perencanaan dari kedua metode diatas terlihat berbeda namun keduanya dipakai dalam perencanaan tebal perkerasan kaku di Indonesia.

Ruas jalan Raden Fatah yang berada di Kecamatan Jambi Timur merupakan prasarana transportasi utama yang digunakan oleh masyarakat saat ini, kondisi strukur perkerasan jalan dan kualitas mutu sangat diutamakan. Banyaknya kendaraan yang melewati seperti kendaraan kecil, kendaraan berpenumpang dan kendaraan berat yang akan menimbulkan beban kepada struktur perkerasan.Ruas Jalan Raden Fatah dahulunya adalah jalan Tanah. Seiring dengan waktu pemerintah Kota Jambi mencoba merubah struktur ruas jalan tersebut menggunakan tipe perkerasan lentur ( Flexible Pavement). Peningkatan volume 
pertumbuhan lalu-lintas kendaraan terutama kendaraan berat seperti truk, jalan tersebut mengakibatkan kelebihan kapasitas daya dukung (Over Load) yang membuat jalan tersebut rusak sebelum mencapai umur rencana. Maka Pemerintah Kota Jambi melakukan kajian ulang dengan mencoba merencanakan pembangunan jalan tersebut dengan menggunakan Metode Pekerasan Kaku (Rigid Pavement ) sepanjang $4 \mathrm{~km}$ dengan bentang $6 \mathrm{~m}$ yang diharapkan dengan ditingkatkan jalan tersebut, arus lalulintas menjadi lancer dan memudahkan pengangkutan hasil sumber daya alam berupa hasil pertanian, peternakan dan pertambangan didaerah tersebut.Berdasarkan uraian tersebut maka penulis melakukan Perbandingan, dari parameter-parameter perencanaan tebal perkerasan kaku antara metode AASHTO 1993 dengan metode Pd.T.14-2003 pada perencanaan Jalan Raden Fatah Jambi.

Dalam melakukan perencanaan perkerasan beton semen untuk jalan yang melayani lalu lintas rencana lebih dari satu juta sumbu kendaraan niaga harus didasarkan Pd.T.14-2003 :

- Menganalisa Lalu-Lintas dan komposisinya selama umur rencana (20 tahun).

- Kelas dan Fungsi Jalan.

- Kekuatan tanah dasar yang dinyatakan dengan CBR (\%)

- Jenis Bahu jalan atau tampa bahu jalan.

- Jenis Perkerasan.

Parameter Perencanaan Perkerasan Kaku pada AASHTO 1993 adalah :

1. Analisa Lalu-lintas (Traffic Design) Parameter lalu-lintas didasarkan pada komulatif beban gandar standar ekivalen (Equivalent Single Axle Load, ESAL). Perhitungan untuk ESAL ini didasarkan pada konversi lalu-lintas yang lewat terhadap beban gandar standar 8,16 ton dan mempertimbangkan umur rencana, volume lalu-lintas,faktor distribusi arah dan lajur, nilai ESAL dengan rumus $\left(\mathrm{W}_{18}\right)$ sebagai berikut :

$$
\mathrm{W}_{18}=\sum_{\mathrm{N}_{1}}^{\mathrm{N}_{\mathrm{n}}} \mathrm{x} \mathrm{LHR}_{\mathrm{J}} \mathrm{x} \mathrm{VDF}_{\mathrm{J}} \times \mathrm{D}_{\mathrm{D}} \times \mathrm{D}_{\mathrm{L}} \times 365
$$

$\mathrm{LHR}_{\mathrm{J}}=$ Jumlah Lalu-lintas Rata-rata

$\mathrm{VDF}_{\mathrm{J}}=$ Vehicle Damage factor untuk jenis kendaraan yang mewakili

$\mathrm{D}_{\mathrm{D}}=$ Distribusi arah 0,3-0,7. Umum-Diambil 0,5

$\mathrm{D}_{\mathrm{L}}=$ Distribusi lajur 1 arah $(100 \%)$

2. Menentukan Nilai Vehicle Damage Factor (VDF) Menurut Ari Suryawan (2015), nilai-nilai VDF dari berbagai sumber semuanya tidak ada kesamaan, bahkan ada nilai yang berbeda sangat signifikan untuk jenis kendaraan yang mewakili sama.

3. Menentukan Nilai Reliability $\left(\mathbf{R}_{1}\right)$ Nilai Reliability adalah suatu kemungkinan bahwa tingkat pelayanan dapat tercapai pada tingkatan tertentu dari sisi pandang pengguna jalan sepanjang umur rencana. Nilai Reliability berkisaran antara 50\% sampai $99.99 \%$.

4. Kemampuan Layanan Serviceability kemampuan layanan adalah kemampuan struktur perkerasan tersebut dalam menahan beban volume kendaraan dan pengaruh lingkungan selama umur kinerjanya, untuk menghitung Serviceability loss menggunakan rumus :

$\Delta \mathrm{PSI}=\mathrm{P}_{\mathrm{o}}-\mathrm{P}_{\mathrm{t}}$

$\mathrm{Po}=$ Initial serviceability untuk rigid

Pavement $: \mathrm{P}_{\mathrm{o}}=4,5$ 
$\mathrm{Pt}=$ Terminal serviceability antar 2-3.

5. Menentukan CBR dan Modulus Reaksi tanah dalam perencanaan perkerasan kaku digunakan untuk penentuan nilai parameter modulus reaksi tanah ( modulus of subgrade reaction $: k$ ) dengan persamaan $\mathrm{k}=\frac{\mathrm{MR}}{19,4}=\frac{1,500 \mathrm{xCBR}}{19,4}$

6. Penentuan Tebal Plat berdasarkan rumus $\log _{10} \mathrm{~W}_{18}$ pada AASHTO 1993 dalam Ari Suryawan 2009.

Parameter Perencanaan Perkerasan Kaku dengan Metode Pd.T.14-2003 :

1. Analisa Lalu-lintas, kendaraan yang ditinjau untuk perencanaan perkerjaan beton semen adalah kendaraan yang mempunyai berat total minimum 5 ton. Konfigurasi sumbu untuk perencanaan terdiri atas 4 jenis,yaitu :

- Sumbu tunggal roda tunggal (STRT).

- Sumbu tunggal roda ganda (STRG).

- Sumbu tandem roda ganda (STdRG).

- Sumbu tridom roda ganda (STdRG).

2. Pertumbuhan Lalu-lintas $\left(\mathbf{R}_{2}\right)$, volume lalu-lintas akan bertambah sesuai dengan umur rencana atau sampai tahap dimana kapasitas jalan dicapai dengan faktor, laju pertumbuhan ( $\mathrm{i}$ ) pertahu ( \% ) dapat dilihat dari tabel faktor pertumbuhan lalu-lintas yang ada pada Pd.T.14-2003 dalam Ari Suryawan 2009.

3. Faktor Keamanan Beban ( $\mathbf{F K}_{\mathbf{B}}$ ), Pada penentuan beban rencana, beban sumbu dikalikan dengan nilai factor keamanan beban $\left(\mathrm{FK}_{\mathrm{B}}\right)$. Faktor keamanan beban ini digunakan berkaitan adanya berbagai tingkat realibilitas perencanaan berdasarkan kegunaan.

4. CBR dan Modulus Reaksi Tanah Dasar, Menurut Pd.T.14-2003 Persyaratan teknis daya dukung tanah dasar ditentukan dengan pengujian CBR insitu sesuai dengan SNI 03-1731-1989 atau CBR laboratorium sesuai dengan SNI 03-1744-1989, masing-masing untuk perencanaan tebal pekerasan lama dan perkerasan jalan baru.

5. Lapis Pondasi Bawah, Bahan pondasi bawah yang digunakan dalam perencanaan perkerasan beton semen dapat berupa :

- Bahan berbutir.

- Stabilisasi atau dengan beton kurus giling padat (Lean Rolled Concrete).

- Campuran beton kurus (Lean-Mix Concrete).

6. Bahu Jalan, Bahu jalan terbuat dari bahan lapisan pondasi bawah dengan atau tanpa lapisan penutup beraspal beton semen. Yang dimaksud dengan bahu jalan atau bahu beton semen adalah bahu yang dikunci dan diikatkan dengan lajur lalu lintas dengan lebar minimum $1,50 \mathrm{~m}$, atau bahu yang menyatu dengan lajur lalu lintas selebar $0,60 \mathrm{~m}$, yang juga dapat mencangkup saluran dan kereb.

7. Penentuan Tebal Pelat, Tebal pelat taksiran dipilih dan total fatik serta kerusakan erosi dihitung berdasarkan komposisi lalu-lintas selama umur rencana. Jika kerusakan fatik atau erosi lebih dari $100 \%$, tebal taksiran dinaikan dan proses perencanaan diulangi. 


\section{METODE PENELITIAN}

Tahapan Pelaksanaan Penilitian dimulai pengumpulan data, adapun data yang dimaksud adalah data sekunder, (LHR, CBR dan berupa catatan serta laporan yang telah ada. Kemudian dianalisis dengan metode AASHTO 1993 dan metode Pd.T.14-2003.

Langkah selanjutnya adalah menganalisa parameter-parameter yang berperan pada kedua metode, yaitu metode AASHTO 1993 dan metode Pd.T.142003, kemudian memberikan rekomendasi metode mana yang paling cocok dan sesuai digunakan pada jalan Raden Fatah Jambi.

\section{HASIL DAN PEMBAHASAN}

Metode AASHTO 1993. Dari data yang telah ada maupun data yang baru diperoleh berdasarkan hasil survey yang dilakukan, dengan nilai CBR 6\% maka parameter desain dapat dilihat dibawah ini:

1. Umur Rencana $=20$ tahun

2. Faktor Distribusi Arah $\mathrm{D}_{\mathrm{A}}=0,5$

3. Jumlah Lajur $100 \%=1$

4. Standar normal deviate $\mathrm{Z}_{\mathrm{R}}=1,282$

5. Standar Deviation So $=0,4$

6. Reliability $\mathrm{R}_{1}=90 \%$

7. Lalu-lintas,ESAL $=1174584217$

Dari Parameter diatas, tebal perkerasan kaku (Rigid Pavement) dengan nilai D didapat dari coba-coba.

$\log _{10} 1174858252=1,282 \times 0,4+7,35 \log _{10}(7+1)-0,20+\frac{\log _{10}\left(\frac{\Delta P S I}{4,5-1,5}\right)}{1+\frac{1,642 \times 10^{7}}{(7+1)}}+(4,22-$ $\left.0,32 \mathrm{p}_{\mathrm{t}}\right) \times \log _{10} \frac{S_{C C_{d^{x}\left(7^{0,75}-1,132\right)}}}{215,63 \times J x\left(7^{\left.\left.0,75-\frac{18,42}{\left(E_{C}\right.}: k\right)^{0,25}\right)}\right.}$

$9,0700=9,07$ inch

Diperoleh tebal rigid pavement dengan metode AASHTO 1993 adalah 9,07 inch. atau dibulatkan 9 inch $=23,03 \mathrm{~cm}(23 \mathrm{~cm})$.

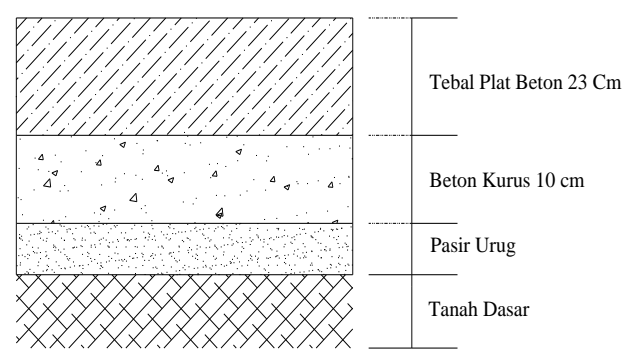

Tanah dasar 6\%

Gambar 2. Penampang potongan perkerasan kaku metode AASHTO 1993.

Dengan Metode Pd.T.14-2003, Data yang telah diperoleh, atau data yang didapat hasil survey terbaru 2017 sebagai berikut :

1. CBR Tanah Dasar $=6 \%$

2. CBR Efektif $=35 \%$

3. Umur Rencana $=20$ tahun

4. Jumlah Sumbu Niaga Rencana $\left(\mathrm{JSKN}_{\mathrm{R}}\right)=7,53 \times 10^{6}$

5. Faktor Keamanan Beban $=1,1$ 
6. Mutu Beton $\mathrm{K}=350$

7. Bahu Jalan = TIDAK

8. Data Lalu-lintas harian rata-rata 2017 :

- Kend,Ringan $=639$

- Pick Up = 262

- Bus Kecil 2as = 57

- Bus Sedang 2as = 4

- Truk Kecil 2as = 396

- Truk Sedang 2as = 511

- Truk Besar 2as = 59

- Truk Besar 3as = 22

- Truk Trailer 6as = 4

Jumlah kendaraan melintas dalam 1 hari sebesar 1954. Dengan tebal asumsi 220 mm, CBR Effektif 35\% didapat :

Tegangan Ekivalent,TE :
I. $\quad$ STRT $=0,82$
II. $\quad \mathrm{STRG}=1,33$
III. $\quad$ STdRG $=0,28$

Faktor Erosi,FE :
I. $\quad \mathrm{STRT}=2,07$
II. $\quad \mathrm{STRG}=2,68$
III. $\quad \mathrm{STdRG}=2,78$

Dari data diatas dihitung analisa Fatik dan Erosi pada tebal $220 \mathrm{~mm}$, seperti pada tabel.1 yang dapat dilihat dihalaman berikutnya.

Tabel 1 : Perhitungan Analisa Fatik dan Erosi

\begin{tabular}{|c|c|c|c|c|c|c|c|c|}
\hline \multirow[b]{2}{*}{ Jenis } & \multirow{2}{*}{$\begin{array}{l}\text { Beban } \\
\text { Sumbu }\end{array}$} & \multirow{2}{*}{$\begin{array}{c}\text { Beban } \\
\text { Rencana }\end{array}$} & \multirow{2}{*}{$\begin{array}{c}\text { Repetisi } \\
\text { Yang }\end{array}$} & \multirow{2}{*}{$\begin{array}{c}\text { Faktor } \\
\text { Tegangan }\end{array}$} & \multicolumn{2}{|c|}{ Analisa Fatik } & \multicolumn{2}{|c|}{ Analisa Erosi } \\
\hline & & & & & Repetisi & Persen & Repetisi & Persen \\
\hline \multirow[t]{2}{*}{ Sumbu } & $\operatorname{ton}(\mathrm{Kn})$ & Per Roda & Terjadi & dan & Ijin & Rusak & Ijin & Rusak \\
\hline & & $(\mathrm{Kn})$ & & Erosi & & $(\%)$ & & $(\%)$ \\
\hline 1 & 2 & 3 & 4 & 5 & 6 & $(7)=(4) * 100 /(6)$ & 8 & $(9)=(4) * 100 /(8)$ \\
\hline \multirow[t]{5}{*}{ STRT } & 80 & 44 & $4,0 \times 10^{6}$ & $\mathrm{TE}=0,82$ & TT & 0 & $75 \times 10^{6}$ & 5,33 \\
\hline & 60 & 33 & $2,3 \times 10^{6}$ & FRT $=0,21$ & TT & 0 & TT & 0 \\
\hline & 50 & 27,5 & $6,3 \times 10^{6}$ & $\mathrm{FE}=2,07$ & TT & 0 & TT & 0 \\
\hline & 20 & 11 & $6,5 \times 10^{6}$ & & TT & 0 & TT & 0 \\
\hline & 10 & 5,5 & $4,2 \times 10^{6}$ & & TT & 0 & TT & 0 \\
\hline \multirow[t]{3}{*}{ STRG } & 100 & 27,5 & $6,2 \times 10^{6}$ & $\mathrm{TE}=1,33$ & $8 \times 10^{6}$ & 77,5 & $10 \times 10^{6}$ & 62 \\
\hline & \multirow{2}{*}{40} & \multirow{2}{*}{11} & \multirow{2}{*}{$6,4 \times 10^{6}$} & $\mathrm{FRT}=0,34$ & \multirow{2}{*}{ TT } & \multirow{2}{*}{0} & \multirow{2}{*}{ TT } & \multirow{2}{*}{0} \\
\hline & & & & $\mathrm{FE}=2,68$ & & & & \\
\hline \multirow[t]{3}{*}{ STdRG } & 180 & & $2,3 \times 10^{6}$ & $\mathrm{TE}=1,11$ & TT & 0 & $8,5 \times 10^{6}$ & 27,06 \\
\hline & \multirow{2}{*}{140} & \multirow{2}{*}{19,25} & \multirow{2}{*}{$4 \times 10^{6}$} & $\mathrm{FRT}=0,28$ & \multirow{2}{*}{$\mathrm{TT}$} & \multirow{2}{*}{0} & \multirow{2}{*}{ TT } & \multirow{2}{*}{0} \\
\hline & & & & $\mathrm{FE}=2,78$ & & & & \\
\hline TAL & & & & & $77,5 \%$ & $100 \%$ & $94,39 \%$ & $100 \%$ \\
\hline
\end{tabular}

Sumber : Hasil perhitungan 2017

Dari tabel diambil tebal $220 \mathrm{~mm}$, karena dari perhitungan diatas presentase kerusakan akibat fatik dan erosi lebih kecil dari 100\%, maka tebal plat beton aman digunakan. 


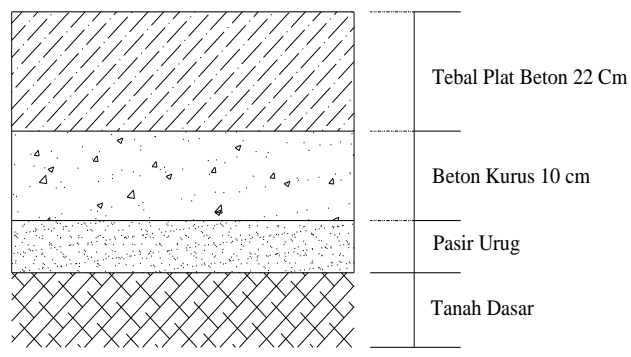

Gambar 3. Penampang potongan perkerasan kaku metode Pd.T.14-2003.

Hasil Analisa Perbandingan Antara Kedua Parameter Metode AASHTO 1993 dan Pd.T.14-2003 dapat dilihat sebagai berikut :

\section{a. CBR}

Menurut AASHTO 1993CBR Tanah menggunakan nilai CBR Relatif 6\%, Dan menggunakan nilai Resilient Modulus Tanah berdasarkan $M r$. dan berdasarkan Metode Pd.T.14-2003 CBRTanah menggunakan CBR efektif $35 \%$ yang didapat dari Grafik Koreksi Efektive Modulus Of Subgrade Reaction.

b. Lalu-Lintas Harian Rata-rata (LHR)

Metode AASHTO 1993 Lalu-Lintas Rencana dinyatakan dalam W18 . Perhitungan ESAL yang didasarkan konversi lalu-lintas terhadap beban gandar standar 8,16 ton dan mempertimbangkan volume lalu-lintas, faktor distribusi arah $\left(\mathrm{D}_{\mathrm{A}}\right)$ dan Distribusi Lajur $\left(\mathrm{D}_{\mathrm{L}}\right)$.

Sedangkan pada metode Pd.T.14-2003

Lalu-Lintas Rencana hanya menggunakan jumlah komulatif sumbu kendaraan niaga perhari sesuai dengan konfigurasi sumbu pada tiap jenis kendaraan dan mempertimbangkan faktor distribusi Lajur,Faktor Lalu- lintas yang mempunyai berat total minimum 5 ton dalam JSKN.

c. Faktor Keamanan

Dengan Metode AASHTO 1993 dinyatakan dengan faktor keandalan Reliability $\left(\mathrm{R}_{1}\right)$ Untuk mengetahui bahwa perkerasan yang direncanakan akan tetap memuaskan selama umur layanan. dan mengkaji nilai Standar Deviasi $\left(\mathrm{S}_{\mathrm{o}}\right.$ ) untuk memperkecil kemungkinan terjadinya selisih (Deviasi). Sedangkan Pd.T.14-2003 Hanya memperhitungkan umur rencana berdasarkan Nilai Repetisi Sumbu Rencana dan dinyatakan dengan Faktor Keamaan Beban $\left(\mathrm{F}_{\mathrm{kb}}\right)$.

\section{d. Penentuan Tebal Plat Beton}

Untuk metode AASHTO 1993 Hasil perhitungan ESAL total dengan menggunakan persamaan $\mathrm{W}_{18}$. daipakai untuk menentukan tebal plat beton berdasarkan rumus Penurunan $\log _{10} \mathrm{~W}_{18}$ dari ketetentuan AASHTO 1993. Sedangkan metode Pada Metode Pd.T.14-2003 Tebal plat asumsi dinyatakan aman selama umur rencana apabila nilai yang didapat dari Perhitungan ekivalen dan Analisis Fatik Erosi mempunyai Nilai Persen Rusak yang kecil dari $100 \%$.

Dari hasil perbandingan diantara metode AASHTO 1993 dan Pd.T.14-2003 di atas, penulis menyimpulkan metode AASHTO 1993 sangat cocok digunakan pada jalan Raden Fatah Jambi. Karna jalan tersebut berdasarkan hasil survey yang telah dilakukan tahun 2017 memiliki Lalu-lintas kendaraan harian yang rendah. 


\section{SIMPULAN}

Dari hasil analisis yang telah dilakukan, maka penulis dapat menyimpulkan sebagai berikut :

1. Tebal Pelat Beton berdasarkan perhitungan menggunakan metode AASHTO 1993 adalah $23 \mathrm{~cm}$, dan metode Pd.T.14-2003 adalah 22cm. Adanya perbedaan hasil perhitungan tebal plat beton antara Metode AASHTO 1993 dan Pd.T.14-2003 disebabkan oleh parameter input masing-masing metode. Untuk metode AASHTO 1993 dalam menentukan nilai CBR tanah menggunakan CBR Relatif berdasarkan besaran 6\%. Menurut Pd.T.14-2003 CBR yang digunakan adalah CBR Efective ditentukan dengan pengujian insitu atau CBR laboratorium yang diaplikasikan menggunakan Grafik Koreksi Efective Modulus of Subgrade Reactoin, dengan mempertimbangkan nilai JSK . CBR Pd.T.14-2003 yang didapat dari perhitungan yang dilakukan sebesar $35 \%$.

Untuk menganalisa Laju Harian Rata-Rata (LHR), ke dua metode ini memiliki analisa yang berbeda. AASHTO 1993 mengacu kepada nilai komulatif beban gandar standar ekivalen (Equivalent Standar Axle Load) dengan konversi lalu-lintas yang lewat terhadap beban gandar standar 8,16 ton dan mempertimbangkan umur rencana,volume lalu-lintas,faktor distribusi arah dan lajur. Sedangkan Pd.T.14-2003 Lalu-lintas hanya menggunakan jumlah komulatif sumbu kendaraan niaga perhari sesuai dengan konfigurasi sumbu pada setiap jenis kendaraan yang mempunyai berat total minimum 5 ton dalam JSKN. Metode AASHTO juga memperhitungan nilai Reliability untuk mengetahui bahwa perkerasan yang direncanakan akan tetap memuaskan selama umur layanan dan memperkecil kemungkinan terjadinya selisih (Deviasi). Namun berbeda dengan metode Pd.T.14-2003, metode ini tidak menggunakan nilai reliability, hanya memperhitungkan umur rencana berdasarkan nilai repetisi sumbu dengan dinyatakan faktor keamanan beban $\left(\mathrm{F}_{\mathrm{kb}}\right)$. Pada kedua metode ini saat menentukan tebal perkerasan juga menggunakan cara yang berbeda, AASHTO menggunakan persamaan $\mathrm{W}_{18}$ dari nilai ESAL total lalu menggunakan nilai penurunan $\log _{10} \mathrm{~W}_{18}$ yang sudah di konversikan Pada pedoman rumus ketetapan AASHTO 1993 dalam Ary Suryawan tahun 2015. Untuk Pd.T.14-2003 tebal plat di dapat apabila hasil perhitungan tebal plat asumsi dinyatakan aman selama umur rencana dengan memperhitungkan analisis Fatik Erosi apabila memiliki nilai persen rusak yang kecil dari $100 \%$.

2. Parameter - Parameter yang digunakan oleh kedua Metode ini intinya adalah untuk mendapatkan ketebalan perkerasan kaku yang sesuai dengan faktor beban lalu lintas. Namun kedua metode ini sama-sama didasarkan pada

\section{Saran} kemampuan beton dalam menahan beban lentur.

Adapun beberapa saran yang ingin penulis sampaikan adalah :

1. Untuk mendapatkan hasil yang sesuai dengan harapan, perencana harus tetap mengikuti ketetapan-ketetapan dan prosedur yang telah ada. Dan perencana harus mempertimbangkan Faktor keamanan dan kelayakan selama umur rencana untuk mengatasi, mengakomodasi kemungkinan melesetnya besaranbesaran desain yang dipakai. 
2. Penulis berharap hasil penelitian ini dapat dijadikan Referensi,wacana perbandingan dan solusi dalam perencanaan perkerasan kaku (Rigid Pavement).

\section{DAFTAR PUSTAKA}

, 2003, Perencanaan Tebal Perkerasan Kaku, Pedoman Perkerasan Jalan Beton Semen (Pd T-14-2003), Departemen Pemukiman dan Prasarana Wilayah, Jakarta.

Ari Suryawan, 2005, Perkerasan Jalan Beton Semen Portland (Rigid Pavement), Jakarta, Beta Offset.

A . Gunawan ,2014, Tugas Akhir Perencanaan Pada Rigid Pavement Berdasarkan Metode AASHTO 1993, UNBARI, Jambi (tidak dipublikasikan).

Athur Wignal, 2003, Teori dan Praktek Proyek Jalan , Jakarta, Erlangga.

Hary Chirstady Hardiyatmo, 2013, Stabilitas Tanah Untuk Perkerasan Jalan, Yogyakarta, Gadjah Mada University Press.

Langgeng Hadhi Pranoto, 2016, Tugas Akhir Perencanaan Perkerasan Lentur Untuk Pelebaran Jalan Batas Kota Jambi-Simpang Sungai Duren , UNBARI, Jambi (tidak dipublikasikan).

M. Hafiz, 2012, Tugas Akhir Perencanaan Tebal Lapis Perkerasan Jalan Dengan Tipe Perkerasan Kaku Untuk LaluLintas Kendaraan Berat di Kota Jambi, UNBARI, Jambi (tidak dipublikasikan).

Silvia Sukirman, 1999, Perencanaan Tebal Struktur Perkerasan Lentur , Bandung, Nova. 